\title{
Addition of Dexmedetomidine to Ropivacaine in Transversus Abdominis Plane Block Potentiates Post-Operative Pain Relief among Laparoscopic Cholecystectomy Patients- A Randomized Controlled Trail
}

\author{
Debarati Goswami ${ }^{1}$, Somnath Dey², Swarup Dutta ${ }^{3}$, Debraj Sur ${ }^{4}$ \\ ${ }^{1}$ Department of Anaesthesiology, BSMCH, Bankura, West Bengal, India. ${ }^{2}$ Department of Anaesthesiology, BSMCH, \\ Bankura, West Bengal, India. ${ }^{3}$ Department of Anaesthesiology, BSMCH, Bankura, West Bengal, India. ${ }^{4}$ Department of \\ Anaesthesiology, BSMCH, Bankura, West Bengal, India.
}

\section{ABSTRACT}

\section{BACKGROUND}

Transversus Abdominis Plane Block (TAPB) is a newer regional anaesthesia technique which is commonly used now a days. It provides analgesia mainly after lower abdominal surgery where parietal wall pain is the major component of pain. Here sensory blockade of lower abdominal wall skin and muscles occur due to local anaesthetic deposition above transversus abdominis muscle. But it has been shown that it also useful in upper abdominal surgeries and retroperitoneal surgeries. We evaluated the effect of addition of dexmedetomidine to ropivacaine in TAP block in a single blind, and prospective, randomized controlled clinical trial.

\section{METHODS}

A total of 60 adult patients, 20 to 50 yrs. of age, of both sexes, ASA physical status I or II were randomized to Group $\mathrm{R}(\mathrm{n}=30)$ receiving TAP block with $20 \mathrm{ml}$ of $0.375 \%$ ropivacaine and $2 \mathrm{ml}$ of normal saline while Group RD $(\mathrm{n}=30)$ received 0.5 $\mathrm{mcg} / \mathrm{Kg}$ of dexmedetomidine diluted in normal saline to make $2 \mathrm{ml}$ and $20 \mathrm{ml}$ of $0.375 \%$ ropivacaine bilaterally followed by general anaesthesia. Hemodynamic responses to surgical incision were noted. Visual analog scale (VAS) scores were assessed on the emergence, then every $1 \mathrm{hr}$. up to $12 \mathrm{hrs}$. And at $24 \mathrm{hrs}$. Time to first rescue analgesic (when VAS $\geq 40 \mathrm{~mm}$ or on demand), duration of postoperative analgesia, incidence of postoperative nausea-vomiting were also noted.

\section{RESULTS}

Intraoperative heart rate decreases in group RD $p<0.05$ ). VAS score at 60 - and 120 min post-operatively was low in group RD $(\mathrm{p}<0.05)$. Duration of analgesia in group $R(255.83 \pm 51.96)$ less than group $R D(405.33 \pm 106.04)$ which is statistically significant. $(\mathrm{p}<0.05)$. No complication or side effect attributed to TAP block, local anaesthetic or dexmedetomidine were noted in any patient.

\section{CONCLUSIONS}

Addition of dexmedetomidine improves quality and duration of analgesia in laparoscopic cholecystectomy patients when used as adjuvant to ropivacaine in TAP block.

\section{KEY WORDS}

Ropivacaine, Dexmedetomidine, Transversus Abdominis Plane Block, PostOperative Analgesia

\author{
Corresponding Author: \\ Somnath Dey, \\ Flat No. C/A, Block-F \\ Meena Residency, \\ Teghoria, Kolkata-157, \\ West Bengal, India. \\ E-mail: iamsomnathdey@gmail.com
}

DOI: 10.14260/jemds/2019/697

Financial or Other Competing Interests: None.

How to Cite This Article:

Goswami D, Dey $S$, Dutta $S$, et al. Addition of dexmedetomidine to ropivacaine in transversus abdominis plane block potentiates post-operative pain relief among laparoscopic cholecystectomy patients- a randomized controlled trail. J. Evolution Med. Dent. Sci. 2019;8(43): 3216-3219, DOI:

10.14260/jemds/2019/697

Submission 03-09-2019,

Peer Review 12-10-2019,

Acceptance 19-10-2019,

Published 28-10-2019. 


\section{BACKGROUND}

The transversus abdominis plane (TAP) block is a newer, increasingly used regional anaesthesia technique that provides analgesia following abdominal surgery. It was introduced in anaesthesia in 2001 by Rafi who used the traditional anatomical landmarks. ${ }^{1}$

In this technique single large bolus injection of local anaesthetic given into an anatomical space between the internal oblique and transversus abdominis muscles. ${ }^{2}$ Transversus Abdominis Plane Block (TAPB) performed through the lumbar triangle of Petit formed by external oblique muscle anteriorly, latissimus dorsi muscle posteriorly, iliac crest inferiorly and is usually identified as a defect $1 \mathrm{~cm}$ above the iliac crest in midaxillary line. With this anatomical landmark, local anaesthetic is injected into the transversus abdominis fascial plane, where anterior branches of thoracolumbar nerves originate from T6 to L1 are located. It has been used most commonly in lower abdominal surgeries like hysterectomy, ${ }^{3}$ appendicectomy, ${ }^{4}$ hernia repair, ${ }^{5}$ caesarean section ${ }^{6}$ and retropubic prostatectomy ${ }^{7}$. But it has been shown to be useful also in upper abdominal surgeries like large bowel resection, ${ }^{2}$ nephrectomy, ${ }^{8}$ laparoscopic cholecystectomy. 9,10 In regional analgesic technique, drugs have mainly peripheral site of action, so minimum systemic side effects occur.

Most of the studies have been done with bupivacaine. Ropivacaine being more cardio stable and safer drug its efficacy on intraoperative as well as postoperative analgesia in patients undergoing laparoscopic cholecystectomy remains yet to be elucidated. Dexmedetomidine is increasingly gaining anaesthesiologists' attention due to its different actions like sedation, anxiolysis, analgesia and sympatholysis.11,12 Dexmedetomidine is an alpha 2 adrenergic agonist, prolongs analgesia when used in neuraxial and peripheral nerve blocks.

Based on the different studies we planned to add dexmedetomidine as adjuvant to ropivacaine in TAP block in laparoscopic cholecystectomy patients to see if any change occurs in quality and duration of analgesia.

\section{METHODS}

After obtaining institutional ethical committee approval and written informed consent, 60 adult patients of 20 to $50 \mathrm{yrs}$., of age of both sex, no of patients calculated from sample size calculator software, American Society of Anesthesiologists (ASA) physical status (PS) I or II, scheduled for elective laparoscopic cholecystectomy under general anaesthesia were recruited in this randomized double-blind controlled clinical trial.(CTRI NO- REF/2017/10/015648). Patients not given consent and patients with body mass index $>30 \mathrm{Kg} / \mathrm{m}^{2}$, having renal and liver function defect, having uncontrolled diabetes mellitus, severe cardiovascular and respiratory diseases, with history of allergy to any of the study drug, and history of abdominal surgery before were excluded from the study. Patients were explained about the procedure in details in the pre-operative visit prior to obtain written informed consent.
Primary outcome of our study was time to request first postoperative analgesic and immediate postoperative visual analogue scale (VAS) and then hourly up to $12 \mathrm{hrs}$. And then 4 hrly., up to $24 \mathrm{hrs}$. Secondary outcomes were intraoperative hemodynamic changes, postoperative hemodynamic changes and any side effects.

The patients fasted for $8 \mathrm{~h}$ pre-operatively. In the operating room, monitors, including non-invasive arterial pressure, electrocardiography, and pulse oximetry were applied. An 18-gauge IV cannula was secured in the peripheral vein on the non-dominant and Depending upon the drug used for premedication, patients were randomly allocated to two groups (Group RD or Group R) using computer generated table with random numbers. The randomisation assignment was kept in sealed opaque envelopes and opened at the time of the 'study drug' preparation.

Group R patients $(n=30)$ received TAP block with $20 \mathrm{ml}$ of $0.375 \%$ ropivacaine and $2 \mathrm{ml}$ of normal saline while Group $\mathrm{RD}(\mathrm{n}=30)$ received $0.5 \mathrm{mcg} / \mathrm{Kg}(2 \mathrm{ml})$ of dexmedetomidine and $20 \mathrm{ml}$ of $0.375 \%$ ropivacaine bilaterally.

The lumbar triangle of Petit, located just anterior to the latissimus dorsi muscle were identified by palpating the iliac crest in an anterior to posterior direction, until the edge of the latissimus dorsi felt. The skin was pierced just cephalic to the iliac crest over the triangle of Petit with a blunt 18-gauge Tuhoy needle after infiltration with $2 \%$ lignocaine. The block was administered following the technique advocated by McDonnell et al. ${ }^{2}$ The needle advanced perpendicular to the skin in the coronal plane until the first resistance of external oblique muscle men countered. Gentle advancement of the needle resulted in a pop sensation as the needle entered the plane between the external and internal oblique fascial layers. A second resistance felt as the needle passed through the internal oblique muscle. A second loss of resistance was encountered when the needle reaches the transversus abdominis fascial plane between the internal oblique and transversus abdominis muscle. A test dose of $1 \mathrm{ml}$ injected to determine resistance to flow and confirm the needle tip placement within the neurovascular plane. After this one of the study solutions injected on each side following careful aspiration to exclude vascular puncture.

Ten min after TAP block, all patients received a standardized general anaesthesia with Fentanyl $2 \mathrm{mcg} / \mathrm{Kg}$, propofol $2 \mathrm{mg} / \mathrm{Kg}$ administered intravenously and atracurium $0.5 \mathrm{mg} / \mathrm{Kg}$ given to facilitate tracheal intubation. Endotracheal tube was used to intubate the trachea and $\mathrm{EtCO}_{2}$ monitoring started to maintain normocapnia and sevoflurane $/ \mathrm{O}_{2} / \mathrm{N}_{2} \mathrm{O}$ mixture was administered. Patients monitored for any signs of inadequate analgesia in the intraoperative period such as sweating, lacrimation, tachycardia ( $>100 / \mathrm{min})$ and hypertension ( $>20 \%$ elevation of baseline mean arterial pressure). After the patient adequately recovered from anaesthesia, and able to assess pain, postoperative analgesia was assessed with VAS $0-100 \mathrm{~mm}$ in the immediate postoperative period and then every $1 \mathrm{hr}$ up to administration of rescue analgesic. The time of administration of rescue analgesic in the form of IV paracetamol $15 \mathrm{mg} / \mathrm{Kg}$ noted when VAS $\geq 40 \mathrm{~mm}$. VAS score assessed by an independent observer who unaware about the allocation. After administration of rescue analgesic, patients were shifted to a postoperative analgesic regimen of 
injection tramadol IV $2 \mathrm{mg} / \mathrm{Kg} 8$ hourly and injection paracetamol 6 hourly up to $24 \mathrm{~h}$. The incidence of postoperative nausea and vomiting noted during the first 24 $h$. Rescue antiemetics given to any patient who complained of nausea or vomiting. Any signs of adverse effects of the technique like local site infection, hematoma formation, local anaesthetic toxicity due to intravascular injection of anaesthetic (Like dizziness, tinnitus, perioral numbness and tingling, lethargy, seizures, signs of cardiac toxicity like atrioventricular conduction block, arrhythmias, myocardial depression and cardiac arrest), peritoneal perforation, bowel perforation, difficulty ambulating or fall and injury secondary to spread of local anaesthetic to nerves of the buttock, lateral thigh or leg in the distribution of the femoral nerve were sought for. ${ }^{13}$

\section{Statistical Analysis}

Raw data were entered into a Microsoft Excel spread sheet and analysed using standard statistical software. Continuous numerical data were expressed as mean and standard deviation (For normally distributed data), or median and inter-quartile range (For data that are not normally distributed). Categorical data were expressed as frequencies and percentages. Normally distributed numerical data between groups were analysed using the Student's t-test. Skewed data between groups were analysed using the MannWhitney U-test. Categorical variables were analysed using the Fisher's exact test or the Pearson's Chi-square test as applicable. All tests were two-tailed. $\mathrm{p}<0.05$ were considered statistically significant.

\section{RESULTS}

\begin{tabular}{|c|c|c|c|}
\hline Group & Variable & Mean \pm S.D. & p Value \\
\hline $\begin{array}{c}\text { Group R } \\
\text { Group RD }\end{array}$ & Age (in years) & $\begin{array}{c}36.26 \pm 7.49 \\
37.4 \pm 8.74\end{array}$ & $>0.05$ \\
\hline $\begin{array}{c}\text { Group R } \\
\text { Group RD }\end{array}$ & Duration of surgery (in mins) & $\begin{array}{c}93.0 \pm 21.35 \\
97.83 \pm 22.54\end{array}$ & $>0.05$ \\
\hline $\begin{array}{c}\text { Group R } \\
\text { Group RD }\end{array}$ & Weight ( in Kg) & $\begin{array}{c}60.03 \pm 10.35 \\
62.2 \pm 12.57\end{array}$ & $>0.05$ \\
\hline $\begin{array}{c}\text { Group R } \\
\text { Group RD }\end{array}$ & HR0 & $\begin{array}{l}79.0 \pm 8.3 \\
79.9 \pm 9.0 \\
\end{array}$ & $>0.05$ \\
\hline $\begin{array}{c}\text { Group R } \\
\text { Group RD }\end{array}$ & MAP0 & $\begin{array}{c}90.3 \pm 12.1 \\
92.4 \pm 9.9\end{array}$ & $>0.05$ \\
\hline \multicolumn{4}{|c|}{$\begin{array}{c}\text { Table 1. Distribution of Patients according to Baseline Vitals and } \\
\text { Demographic Characteristics }\end{array}$} \\
\hline
\end{tabular}

\begin{tabular}{|c|c|c|c|c|}
\hline Group & Sample Size & Variable & Mean \pm S.D. & p Value \\
\hline $\begin{array}{c}\text { Group R } \\
\text { Group RD }\end{array}$ & 30 & HR 10 & $\begin{array}{c}77.87 \pm 7.43 \\
75.83 \pm 6.95\end{array}$ & $>0.05$ \\
\hline $\begin{array}{c}\text { Group R } \\
\text { Group RD }\end{array}$ & 30 & HR 20 & $\begin{array}{c}77.1 \pm 7.83 \\
75.7 \pm 6.84\end{array}$ & $>0.05$ \\
\hline $\begin{array}{c}\text { Group R } \\
\text { Group RD }\end{array}$ & 30 & HR 30 & $\begin{array}{c}78.7 \pm 7.18 \\
77.83 \pm 6.83\end{array}$ & $>0.05$ \\
\hline $\begin{array}{c}\text { Group R } \\
\text { Group RD }\end{array}$ & 30 & HR 40 & $\begin{array}{c}78.77 \pm 5.76 \\
76.0 \pm 5.88\end{array}$ & $>0.05$ \\
\hline $\begin{array}{c}\text { Group R } \\
\text { Group RD }\end{array}$ & 30 & HR 50 & $\begin{array}{c}80.63 \pm 7.23 \\
78.2 \pm 6.32\end{array}$ & $>0.05$ \\
\hline $\begin{array}{c}\text { Group R } \\
\text { Group RD }\end{array}$ & 30 & HR 60 & $\begin{array}{c}80.26 \pm 6.78 \\
77.5 \pm 5.88\end{array}$ & $>0.05$ \\
\hline $\begin{array}{c}\text { Group R } \\
\text { Group RD }\end{array}$ & 30 & HR 70 & $\begin{array}{c}81.13 \pm 7.29 \\
77.23 \pm 7.25\end{array}$ & $<0.05$ \\
\hline $\begin{array}{c}\text { Group R } \\
\text { Group RD }\end{array}$ & 30 & HR 80 & $\begin{array}{c}84.46 \pm 9.86 \\
79.13 \pm 8.44\end{array}$ & $<0.05$ \\
\hline \multicolumn{7}{|c|}{ Table 2. Distribution of Patients according to Changes in } \\
\multicolumn{5}{|c|}{ Heart Rate during Surgery } \\
\hline
\end{tabular}

Age, duration of surgery, weight, baseline vitals were comparable between groups. Sex distribution between groups were comparable. The comparison between groups showing that at 70 and 80 minutes intraoperatively heart rate significantly low in group $\mathrm{RD}(\mathrm{p}<0.05)$. The groups are comparable regarding intraoperative mean arterial blood pressure.

\begin{tabular}{|c|c|c|c|c|}
\hline Group & Sample Size & Variable & Mean \pm S.D. & p Value \\
\hline $\begin{array}{c}\text { Group R } \\
\text { Group RD }\end{array}$ & 30 & MAP 10 & $\begin{array}{c}88.83 \pm 10.45 \\
91.3 \pm 8.71\end{array}$ & $>0.05$ \\
\hline $\begin{array}{c}\text { Group R } \\
\text { Group RD }\end{array}$ & 30 & MAP 20 & $\begin{array}{c}86.56 \pm 8.79 \\
88.23 \pm 8.24\end{array}$ & $>0.05$ \\
\hline $\begin{array}{c}\text { Group R } \\
\text { Group RD }\end{array}$ & 30 & MAP 30 & $\begin{array}{c}85.46 \pm 8.23 \\
88.06 \pm 7.58\end{array}$ & $>0.05$ \\
\hline $\begin{array}{c}\text { Group R } \\
\text { Group RD }\end{array}$ & 30 & MAP 40 & $\begin{array}{c}85.03 \pm 8.01 \\
86.6 \pm 5.77\end{array}$ & $>0.05$ \\
\hline $\begin{array}{c}\text { Group R } \\
\text { Group RD }\end{array}$ & 30 & MAP 50 & $\begin{array}{c}84.66 \pm 8.06 \\
86.66 \pm 6.44\end{array}$ & $>0.05$ \\
\hline $\begin{array}{c}\text { Group R } \\
\text { Group RD }\end{array}$ & 30 & MAP 60 & $\begin{array}{c}87.53 \pm 7.18 \\
88.7 \pm 5.57\end{array}$ & $>0.05$ \\
\hline $\begin{array}{c}\text { Group R } \\
\text { Group RD }\end{array}$ & 30 & MAP 70 & $\begin{array}{c}90.3 \pm 7.3 \\
90.26 \pm 6.3\end{array}$ & $>0.05$ \\
\hline $\begin{array}{c}\text { Group R } \\
\text { Group RD }\end{array}$ & 30 & MAP 80 & $\begin{array}{c}94.63 \pm 7.49 \\
93.16 \pm 7.38\end{array}$ & $>0.05$ \\
\hline Table 3. Distribution & 30 & Patien & \\
\hline
\end{tabular}

Table 3. Distribution of Patients according to Changes in Mean Arterial Pressure during Surgery

\begin{tabular}{|c|c|c|c|c|c|}
\hline & Group & Sample Size & Mean Rank & Mann Whitney U & p \\
\hline VAS 0 & $\begin{array}{c}\text { Group R } \\
\text { Group RD }\end{array}$ & $\begin{array}{l}30 \\
30 \\
\end{array}$ & $\begin{array}{l}33.90 \\
27.10 \\
\end{array}$ & 348.0 & $>0.05$ \\
\hline VAS 60 & \begin{tabular}{|c|} 
Group R \\
Group RD
\end{tabular} & $\begin{array}{l}30 \\
30\end{array}$ & $\begin{array}{l}37.27 \\
23.73\end{array}$ & 247.0 & $<0.05$ \\
\hline VAS 120 & \begin{tabular}{|c|} 
Group R \\
Group RD
\end{tabular} & $\begin{array}{l}30 \\
30\end{array}$ & $\begin{array}{l}39.73 \\
21.27\end{array}$ & 173.0 & $<0.05$ \\
\hline \multicolumn{6}{|c|}{$\begin{array}{c}\text { Table 4. Distribution of Patients according to Changes in } \\
\text { VAS Score during Surgery }\end{array}$} \\
\hline
\end{tabular}

\begin{tabular}{|c|c|c|c|c|}
\hline Group & Sample Size & Variable & Mean \pm S.D. & p value \\
\hline $\begin{array}{l}\text { Group R } \\
\text { Group RD }\end{array}$ & $\begin{array}{l}30 \\
30\end{array}$ & $\begin{array}{c}\text { Duration of } \\
\text { analgesia(in min) }\end{array}$ & $\begin{array}{c}255.83 \pm 51.96 \\
405.33 \pm 106.04\end{array}$ & $<0.05$ \\
\hline \multicolumn{5}{|c|}{ Table 5. Distribution of Patients according to duration of Analgesia } \\
\hline
\end{tabular}

Post-operative haemodynamics and complications like PONV were comparable between groups. No patients in either group had any complication which can be attributed to TAP block.

\section{DISCUSSION}

Our study shows that addition of dexmedetomidine to ropivacaine decreases intra operative heart rate specially at 70 and 80 minutes intraoperatively. Quality of analgesia improves in dexmedetomidine group which show that VAS score at 60- and 120-min post operatively significantly low in dexmedetomidine group $(\mathrm{p}<0.05)$.Time to $1^{\text {st }}$ rescue analgesic significantly more in group RD (405.33 \pm 106.04 min) than group $R(255.83 \pm 51.96 \mathrm{~min}) .9$ patients in only ropivacaine group and 2 patients in dexmedetomidine with ropivacaine groups required rescue analgesic within $2 \mathrm{hrs}$., post operatively. Prolonged duration of analgesia after TAP block may be due to the fact that transversus abdominis plane is relatively poorly vascularized, so causing drug clearance to slow by reduction of absorption in the blood. ${ }^{14}$

Bhattacharjee $\mathrm{S}$, et $\mathrm{al}^{3}$ showed that TAP block with bupivacaine improves analgesia in patients with total abdominal hysterectomy. Median duration of analgesia was significantly higher in TAP block group (290 min vs. 16 $\min , \mathrm{P}=0.000$ ).

Dexmedetomidine is selective $\alpha 2$ agonist. It causes analgesia through $\alpha 2 \mathrm{~A}$ receptor. It regulates vasoconstriction 
and inhibit noradrenaline release from sympathetic nerve endings, also alpha 2-adrenoceptor activation results in reduced sympathetic tone and augmentation of cardiac-vagal activity. Different previous studies has shown that addition of dexmedetomidine to local anaesthetics in spinal, 15 epidural, ${ }^{16}$ caudal ${ }^{17}$ and brachial plexus block ${ }^{18}$ improves quality and duration of analgesia.

Sinha S, Palta S, et al. ${ }^{19}$ showed in their study that ultrasound-guided TAP block in patients of laparoscopic cholecystectomies with ropivacaine $0.375 \%$ provided superior analgesia in the early post-operative period in comparison to bupivacaine $0.25 \%$. Our study was consistent with the study done by Abdelaal W, Metry AA, et al. ${ }^{20}$ who reported that addition of dexmedetomidine to levobupivacaine in TAP block in patients of abdominoplasty improves analgesia $(205 \pm 10.2 \mathrm{~min}$ vs $181 \pm 12.6 \mathrm{~min})$ and decreases opioid consumption.

Our study has a few limitations like it is difficult to define inadequate analgesia in the intraoperative period as indirect assessment of intraoperative pain by hemodynamic parameters may be unreliable. Post operatively we used VAS score for pain assessment. Illiteracy of patients was the main confounding factor in this study. Most patients had difficulty in understanding the visual analogue scale (VAS).Now a days this block is done with the help of USG, but we used a landmark based anatomical approach. US guidance may increase the efficacy of TAP block, it will not change the primary finding of our study.

\section{CONCLUSIONS}

Addition of dexmedetomidine to the local anaesthetic Ropivacaine in transverses abdominis plane block in patients of open cholecystectomy, improves analgesia and increases time to first analgesic requirement with no significant side effects. The anatomical approach of TAP block is also very safe and effective where USG is not available.

\section{REFERENCES}

[1] Rafi AN. Abdominal field block: a new approach via the lumbar triangle. Anaesthesia 2001;56(10):1024-6.

[2] McDonnell JG, O'Donnell B, Curley G, et al. The analgesic efficacy of transversus abdominis plane block after abdominal surgery: a prospective randomized controlled trial. Anesth Analg 2007;104(1):193-7.

[3] Bhattacharje S, Ray M, Ghose T, et al. Analgesic efficacy of transversus abdominis plane block in providing effective perioperative analgesia in patients undergoing total abdominal hysterectomy: a randomized controlled trial. J Anaesthesiol Clin Pharmacol 2014;30(3):391-6.

[4] Carney J, Finnerty O, Rauf J, et al. Ipsilateral transversus abdominis plane block provides effective analgesia after appendectomy in children: a randomized controlled trial. Anesth Analg 2010;111(4):998-1003.

[5] Aveline C, Le Hetet H, Le Roux A, et al. Comparison between ultrasound-guided transversus abdominis plane and conventional ilioinguinal/iliohypogastric nerve blocks for day-case open inguinal hernia repair. $\mathrm{Br}$ J Anaesth 2011;106(3):380-6.
[6] McDonnell JG, Curley G, Carney J, et al. The analgesic efficacy of transversus abdominis plane block after cesarean delivery: a randomized controlled trial. Anesth Analg 2008;106(1):186-91.

[7] O'Donnell BD, McDonnell JG, McShane AJ. The transversus abdominis plane (TAP) block in open retropubic prostatectomy. Reg Anesth Pain Med 2006;31(1):91.

[8] Hosgood SA, Thiyagarajan UM, Nicholson HF, et al. Randomized clinical trial of transversus abdominis plane block versus placebo control in live-donor nephrectomy. Transplantation 2012;94(5):520-5.

[9] El-Dawlatly AA, Turkistani A, Kettner SC, et al. Ultrasound-guided transversus abdominis plane block: description of a new technique and comparison with conventional systemic analgesia during laparoscopic cholecystectomy. Br J Anaesth 2009;102(6):763-7.

[10] Petersen PL, Stjernholm P, Kristiansen VB, et al. The beneficial effect of transversus abdominis plane block after laparoscopic cholecystectomy in day-case surgery: a randomized clinical trial. Anesth Analg 2012;115(3):527-33.

[11] Lee JH, Jung SY, Kim MH, et al. The effect of dexmedetomidine on propofol injection pain. Korean J Anesthesiol 2014;67(Suppl):S30-1.

[12] Uzun S, Karagoz HA, Kose AE, et al. Dexmedetomidine for prevention of propofol injection pain. J Anaesth Clin Pharmacol 2008;24(4):406-8.

[13] Jankovic Z, Ahmad N, Ravishankar N, et al. Transversus abdominis plane block: how safe is it? Anesth Analg 2008;107(5):1758-9.

[14] Velchev V, Malamov K. The analgesic efficacy of transversus abdominis plane (TAP) block. Khirurgiia (Sofiia) 2010;1:15-18.

[15] Naaz S, Bandey J, Ozair E, et al. Optimal dose of intrathecal dexmedetomidine in lower abdominal surgeries in average Indian adult. J Clin Diagn Res 2016;10(4): UC09-13.

[16] Bajwa SJ, Bajwa SK, Kaur J, et al. Dexmedetomidine and clonidine in epidural anaesthesia: a comparative evaluation. Indian J Anaesth 2011;55(2):116-21.

[17] El-Hennawy AM, Abd-Elwahab AM, Abd-Elmaksoud AM, et al. Addition of clonidine or dexmedetomidine to bupivacaine prolongs caudal analgesia in children. Br J Anaesth 2009;103(2):268-74.

[18] Agarwal S, Aggarwal R, Gupta P. Dexmedetomidine prolongs the effect of bupivacaine in supraclavicular brachial plexus block. J Anaesthesiol Clin Pharmacol 2014;30(1):36-40.

[19] Sinha S, Palta S, Saroa R. Comparison of ultrasoundguided transversus abdominis plane block with bupivacaine and ropivacaine as adjuncts for postoperative analgesia in laparoscopic cholecystectomies. Indian J Anaesth 2016;60(4):264-9.

[20] Abdelaal W, Metry AA, Refaat M, et al. Comparative study between levobupivacine versus levobupivacaine plus dexmedetomidine for transversus abdominis plane block in post-operative pain management after abdominoplasty. J Anesthesiol Crit Care Med 2015;2 (2):1-7. 